\title{
Study on quenching effect of nitrite ions on zinc oxide modified by polyvinylpyrrolidone
}

\author{
Ing Hua Tang ${ }^{1}$, Siti Zarina Mohd So’ad ${ }^{1}$, Hendrik O. Lintang ${ }^{2}$, Leny Yuliati ${ }^{2 *}$ \\ ${ }^{1}$ Department of Chemistry, Faculty of Science, Universiti Teknologi Malaysia, 81310 UTM Johor Bahru, Johor, Malaysia \\ ${ }^{2}$ Centre for Sustainable Nanomaterials, Ibnu Sina Institute for Scientific and Industrial Research, Universiti Teknologi Malaysia, 81310 UTM Johor Bahru, \\ Johor, Malaysia \\ *Corresponding Author: leny@ibnusina.utm.my
}

\section{Article history :}

Received 1 November 2015

Accepted 15 November 2015

\section{GRAPHICAL ABSTRACT}

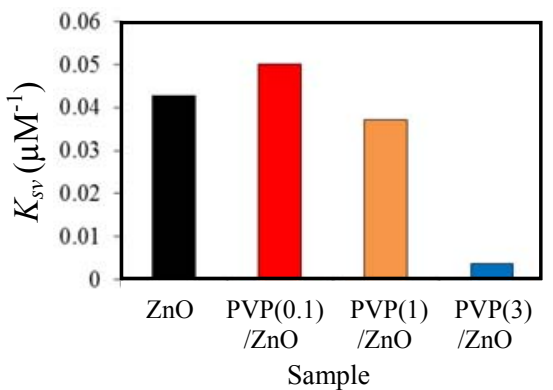

\begin{abstract}
Zinc oxide $(\mathrm{ZnO})$ is appeared to be an attractive material for application for multidisciplinary fields owing to its unique physical and chemical properties. In this study, $\mathrm{ZnO}$ was synthesized using the coprecipitation method, where the zinc acetate was used as the precursor. The $\mathrm{ZnO}$ was further modified by adding different amounts of polyvinylpyrrolidone (PVP) via simple physical mixing method to obtain $\mathrm{PVP} / \mathrm{ZnO}$ composites. The $\mathrm{ZnO}$ and the $\mathrm{PVP} / \mathrm{ZnO}$ composites were characterized using Fourier transform infrared (FTIR), diffuse reflectance ultraviolet-visible (DR UV-Vis), and fluorescence spectroscopy. The FTIR spectra detected the presence of $\mathrm{ZnO}$ group and the functional groups from the PVP. The PVP peaks become more apparent with the increase of the PVP amount. From the DR UVVis spectra, no significant change was observed after modification with the PVP, and all composites showed similar broad absorption band to that of the $\mathrm{ZnO}$. The fluorescence spectra showed that the addition of PVP decreased the emission intensity and red shifted the peak wavelength, indicating certain interactions between the $\mathrm{ZnO}$ and the added PVP. Quenching study was investigated in the presence of nitrite ions $\left(\mathrm{NO}_{2}^{-}\right)$with various concentrations $(2-10 \mu \mathrm{M})$. A linear Stern-Volmer plot was observed and the highest quenching constant rate $\left(K_{S V}\right)$ was obtained on the PVP/ZnO sample with PVP content of 0.1 $\mathrm{wt} \%$. This study demonstrated that the addition of the PVP on the $\mathrm{ZnO}$ improved the interaction between the $\mathrm{ZnO}$ and the $\mathrm{NO}_{2}^{-}$, which will be one of the important factors for sensing and catalytic applications for detection and conversion of $\mathrm{NO}_{2}{ }^{-}$.
\end{abstract}

Keywords: zinc oxide, polyvinylpyrrolidone, quenching study, fluorescence, nitrite ion

(C) 2015 Penerbit UTM Press. All rights reserved http://dx.doi.org/10.11113/mjfas.v11n3.385

\section{INTRODUCTION}

Zinc oxide is one of the key technological materials with great properties and potential applications in numerous fields. Since $\mathrm{ZnO}$ is a wide band gap semiconductor with band gap energy of $3.37 \mathrm{eV}$ at room temperature, it has been used significantly for catalytic, electrical, optoelectronic, and photochemical applications [1]. $\mathrm{ZnO}$ also has high ultraviolet (UV) absorption, large volume to area ratio specifically for the $\mathrm{ZnO}$ nanoparticles, and long life decay which this unique characteristic makes $\mathrm{ZnO}$ a versatile catalyst [2,3]. As a semiconductor photocatalyst, $\mathrm{ZnO}$ covers a high band gap at about 3.37 $\mathrm{eV}$ and absorbs light up to $400 \mathrm{~nm}$ [4]. The $\mathrm{ZnO}$ has been also reported acting as a good sensor for various environmental remediation and monitoring $[5,6]$.

For most applications in catalysis, photocatalysis and sensing technologies, one of the important factors to be developed is improving the capability of the $\mathrm{ZnO}$ to interact with the target molecules. In this study, nitrite ion $\left(\mathrm{NO}_{2}{ }^{-}\right)$is employed as the target molecules. $\mathrm{NO}_{2}^{-}$is a toxic and hazardous compound, which exists in food as a preservative and environment as a result of excessive use of fertilizer in agricultural land. In agricultural area, when human ingest the fertilizer polluted water, the ingested nitrite can be converted to carcinogenic nitrosamine in human digestive system [7]. In order to increase the interactions between the $\mathrm{ZnO}$ and the $\mathrm{NO}_{2}{ }^{-}$, the $\mathrm{ZnO}$ needs to be further modified.

One of the potential modifiers is polymer and polymeric materials. It is known that the surface modification of $\mathrm{ZnO}$ by grafting certain polymers is an effective way to enhance not only the dispersability in polymer matrix, but also the properties of the resulting composites [8]. In recent years, various polymer and polymeric materials have been used to modify $\mathrm{ZnO}$, such as polyethylene oxide [9], poly[2-methoxy-5-(20-ethyl hexyloxy)-phenylenevinylene] [10], carbon nitride [11], and poly(methylmethacrylate) (PMMA) [12]. In this study, the $\mathrm{ZnO}$ was modified with polyvinylpyrrolidone (PVP) since the PVP has good fluorescence property and has been 
reported to give good interactions with nitrate ions $\left(\mathrm{NO}_{3}{ }^{-}\right)$ [13].

\section{EXPERIMENTS}

\subsection{Material Preparations}

To prepare $\mathrm{ZnO}$, zinc acetate dihydrate $\left(\mathrm{Zn}\left(\mathrm{CH}_{3} \mathrm{COO}\right)_{2} \cdot 2 \mathrm{H}_{2} \mathrm{O}\right.$, QRëc) was used as a precursor. Solution A was prepared by dissolving $6.4 \mathrm{~g}$ of sodium hydroxide, (NaOH, QRëc) and $7.28 \mathrm{~g}$ of cetyltrimethyammonium bromide (CTAB, Fisher Scientific) in $100 \mathrm{~mL}$ of unionized water, followed by stirring for $1 \mathrm{~h}$ to obtain the homogeneous solution. Meanwhile, solution $\mathrm{B}$ was prepared by dissolving $4.5 \mathrm{~g}$ of the $\mathrm{Zn}\left(\mathrm{CH}_{3} \mathrm{COO}\right)_{2} \cdot 2 \mathrm{H}_{2} \mathrm{O}$ in $100 \mathrm{~mL}$ of deionized water and subjected to sonication for $30 \mathrm{~min}$. The solution $\mathrm{B}$ was then slowly added to the solution A and heated at $70{ }^{\circ} \mathrm{C}$ for $1 \mathrm{~h}$. The obtained remaining solid was filtered and the obtained solid was washed with deionized water and ethanol $(\mathrm{EtOH}$, $\mathrm{HmbG}$ ), successively. The obtained solid powder was left to dry at room temperature and then calcined at $500{ }^{\circ} \mathrm{C}$ with a heating rate of $1.0^{\circ} \mathrm{C} / \mathrm{min}$ for $1 \mathrm{~h}$ to obtain the $\mathrm{ZnO}$ [14].

On the other hand, the PVP/ZnO composites were prepared by mixing certain mass of polyvinylpyrrolidone K60 (PVP, Sigma Aldrich) with the prepared $\mathrm{ZnO}$, to produce series of $\mathrm{PVP} / \mathrm{ZnO}$ composites with various mass ratios of PVP to $\mathrm{ZnO}$. The composites were denoted as $\operatorname{PVP}(\mathrm{x}) / \mathrm{ZnO}$, where $\mathrm{x}=0.1,1,3 \mathrm{wt} \%$. For the synthesis of $\mathrm{PVP}(1) / \mathrm{ZnO}, 1 \mathrm{~g}$ of the $\mathrm{ZnO}$ was physically mixed with $0.01 \mathrm{~g}$ PVP solid which later ground to obtain the fine mixture of the $\mathrm{PVP}(1) / \mathrm{ZnO}$ composite. The similar procedure was carried out for other $\mathrm{PVP} / \mathrm{ZnO}$ composites.

\subsection{Characterizations}

The properties of the $\mathrm{ZnO}$ and the $\mathrm{PVP} / \mathrm{ZnO}$ samples were investigated using several instruments. The Fourier transformation infrared spectroscopy (FTIR, Thermo Scientific, Nicolet iS50) was used to detect the presence of various functional groups that exist in the samples. Diffuse reflectance UV-Vis spectroscopy (DR UV-Vis, Shimadzu, UV2600) was used to investigate the optical property of the samples. The fluorescence spectroscopy (JASCO, FP-8500) was used at room temperature to examine the fluorescence properties of the samples. The emission spectra of the samples $(0.3 \mathrm{~g})$ were monitored at excitation wavelength of $365 \mathrm{~nm}$.

\subsection{Quenching Test}

The interactions between the samples and the $\mathrm{NO}_{2}{ }^{-}$ were studied using a fluorescence spectroscopy (JASCO, FP-8500) at room temperature. The quenching tests were carried out, where the samples were exposed to various concentrations of $\mathrm{NO}_{2}^{-}(2-10 \mu \mathrm{M}, 10 \mu \mathrm{L})$ and the emission spectra were measured at $365 \mathrm{~nm}$. The interactions between the samples and the $\mathrm{NO}_{2}{ }^{-}$were evaluated from the SternVolmer plots using the Stern-Volmer equation, where the relative emission intensity in the absence and presence of the $\mathrm{NO}_{2}^{-}$was plotted towards the concentration of the $\mathrm{NO}_{2}{ }^{-}$.

\section{RESULTS AND DISCUSSION}

The chemical structure of the synthesized $\mathrm{ZnO}$ and the PVP/ZnO samples were examined using FTIR spectroscopy. Figure 1 shows the FTIR spectra for the $\mathrm{ZnO}$, the $\mathrm{PVP} / \mathrm{ZnO}$ samples, and the PVP as the reference. As shown in Figure 1 (a), the prepared $\mathrm{ZnO}$ showed a sharp peak at $419.97 \mathrm{~cm}^{-1}$ that was responsible for the stretching mode for $\mathrm{Zn}-\mathrm{O}$ [15], indicating the successful synthesis of the $\mathrm{ZnO}$. All the PVP/ZnO samples showed the presence of $\mathrm{Zn}-\mathrm{O}$ stretching as well as two peaks appeared at 1525 and $1423 \mathrm{~cm}^{-1}$ that were assigned to $\mathrm{C}=\mathrm{O}$ and $\mathrm{C}-\mathrm{N}$ stretching, which came from the PVP. As shown in the Fig. 1(e), the PVP showed two main peaks at 1650.50 and $1423.52 \mathrm{~cm}^{-1}$ that were assigned to $\mathrm{C}=\mathrm{O}$ and $\mathrm{C}-\mathrm{N}$ stretching [16]. The shifting observed on the PVP/ZnO samples might be due to the hydrogen bonding and electrostatic interaction between the $\mathrm{ZnO}$ and the functional group in the PVP [15]. When the amount of PVP in the PVP/ZnO composite increased, the intensity of $\mathrm{C}=\mathrm{O}$ stretching and $\mathrm{C}-\mathrm{N}$ stretching also increased due to the increment amount of PVP containing in $\mathrm{PVP} / \mathrm{ZnO}$ composites. The peak observed around 3000 $\mathrm{cm}^{-1}$ was assigned to $\mathrm{CH}$ stretching while around $700 \mathrm{~cm}^{-1}$ was assigned to $\mathrm{C}-\mathrm{C}$ stretching vibration. The peak observed at $3446.83 \mathrm{~cm}^{-1}$ was assigned to the $\mathrm{OH}$ stretching vibration. The $\mathrm{OH}$ peak might come from water molecules that were present in the composites. This happened because the PVP is hydrophilic in nature, which causing the composites to adsorb moisture from the atmosphere.

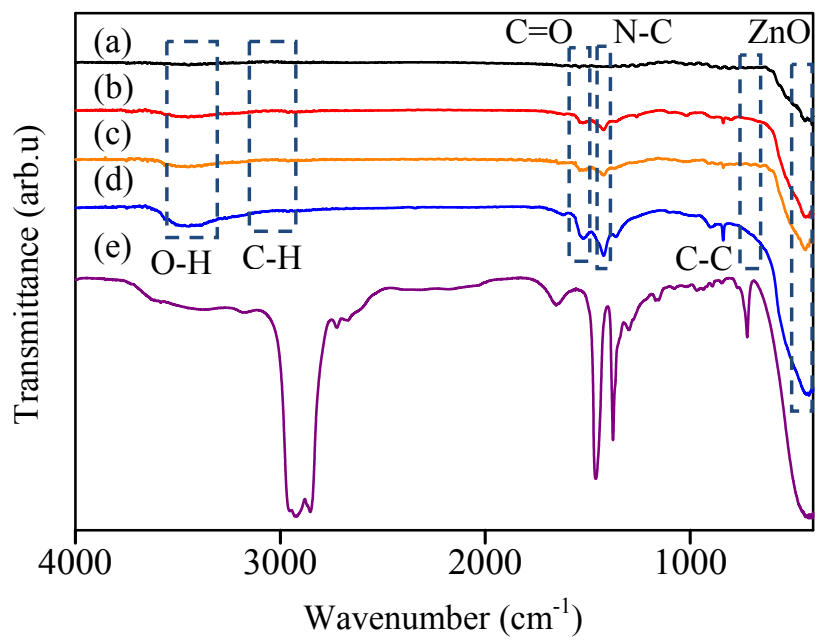

Fig. 1 FTIR spectra for (a) $\mathrm{ZnO}$, (b) $\mathrm{PVP}(0.1) / \mathrm{ZnO}$, (c) $\mathrm{PVP}(1) / \mathrm{ZnO}$, (d) PVP(3)/ZnO, and (e) PVP

The optical property of the $\mathrm{ZnO}$, the $\mathrm{PVP} / \mathrm{ZnO}$ samples, and the PVP was investigated using DR UV-Vis 
spectroscopy. From Fig. 2(a), the $\mathrm{ZnO}$ that gave a strong and broad peak centered at $330 \mathrm{~nm}$, suggesting its capability to absorb UV light region and high transparency in the visible range [17]. While all $\mathrm{PVP} / \mathrm{ZnO}$ samples showed the absorption peak of $\mathrm{ZnO}$, increasing the loading amount of the PVP slightly increased the absorption band around $370 \mathrm{~nm}$. As shown in Fig. 2(e), the PVP showed intense narrow bands centered at 265 and $370 \mathrm{~nm}$, indicating the presence of $\mathrm{C}=\mathrm{O}$ and $\mathrm{N}-\mathrm{C}$ groups, respectively. The band centered at $265 \mathrm{~nm}$ may be assigned to $\mathrm{n} \rightarrow \pi *$ transition between the oxygen lone pairs and the vacant $\pi^{*}$ orbital of the pyrrolidone ring. The absorption band appeared at $370 \mathrm{~nm}$ might be due to the chargetransfer transitions of electrons excited from the carbonyl lone pair to the adjacent carbon atom in pyrrolidone ring [18].

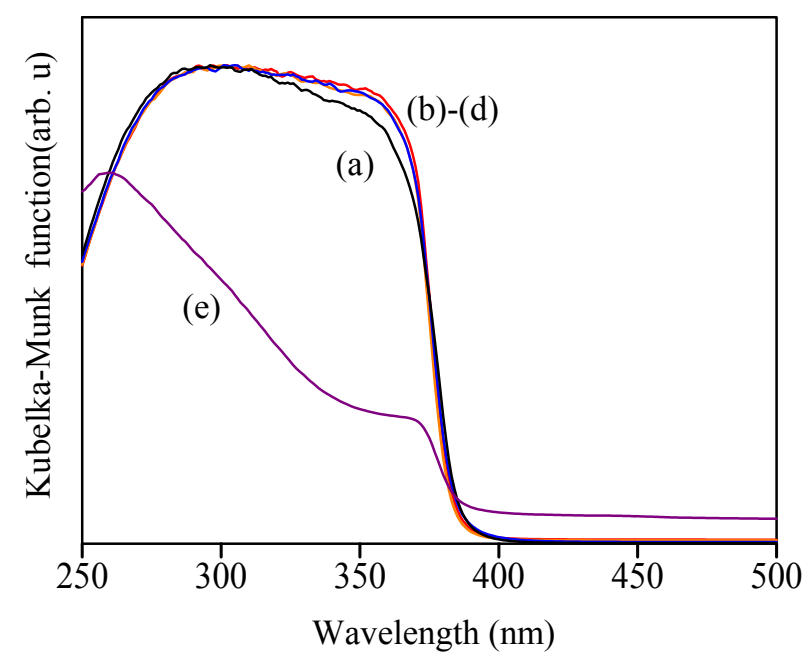

Fig. 2 DR UV-Vis spectra for (a) $\mathrm{ZnO}$, (b) $\mathrm{PVP}(0.1) / \mathrm{ZnO}$, (c) PVP(1)/ZnO, (d) PVP(3)/ZnO, and (e) PVP

Figure 3 shows the emission spectra of the prepared $\mathrm{ZnO}$ and $\mathrm{PVP} / \mathrm{ZnO}$ composites. As shown in Fig. 3(a), $\mathrm{ZnO}$ showed the emission peak at $517 \mathrm{~nm}$ when excited at $365 \mathrm{~nm}$. The emission peak at $517 \mathrm{~nm}$ has been recognized as the green emission of $\mathrm{ZnO}$, reflecting the presence of oxygen defect on the surface and deep level of the $\mathrm{ZnO}$ [19]. On the other hand, all the PVP/ZnO composites have lower emission intensity compared to the $\mathrm{ZnO}$. The fluorescence intensity of $\mathrm{PVP} / \mathrm{ZnO}$ composites decreased because of the surface defect level increased the nonradiative transitions [20]. Other than the reduced emission intensity, the addition of PVP shifted the emission peak to longer wavelength. The decrease in fluorescence intensity and the peak shifting strongly indicated that there were interactions exist between the PVP and $\mathrm{ZnO}$ [21]. The results of the fluorescence spectra were found to be in good agreement with the results of the FTIR spectra.

The as-prepared $\mathrm{ZnO}$ and the composite were further tested for its ability to interact with the hazardous $\mathrm{NO}_{2}^{-}$. The interaction ability of $\mathrm{ZnO}$ and the composites towards the $\mathrm{NO}_{2}^{-}$was investigated using Stern-Volmer plot, where the obtained gradient represented the interaction strength. In the Stern-Volmer plot, the relative emission intensity can be expressed as a function of the $\mathrm{NO}_{2}^{-}$concentrations, according to the Stern-Volmer equation (Eq. 1),

$\frac{I_{o}}{I}=K_{s v}[Q]+1$

where $I_{o}$ and $I$ are emission intensities obtained in the absence and presence of $\mathrm{NO}_{2}^{-}$, respectively, $Q$ is the concentration of $\mathrm{NO}_{2}^{-}$, and $K_{s v}$ is the Stern-Volmer quenching constant. Figure 4 shows the emission spectra for $\mathrm{ZnO}$, where the increase in concentration of $\mathrm{NO}_{2}^{-}(0-10$ $\mu \mathrm{M})$ further quenched the emission intensity. The SternVolmer plot is shown in the inset of Fig. 4, where the relative emission intensity was found to be in a linear function with the increase in the $\mathrm{NO}_{2}{ }^{-}$concentration $(0-10$ $\mu \mathrm{M})$. This result clearly indicated that there is interaction between the $\mathrm{ZnO}$ sample and the $\mathrm{NO}_{2}{ }^{-}$. One of the possible interactions would be an electrostatic interaction [22]. The $K_{s v}$ value for the $\mathrm{ZnO}$ was determined to be $0.04 \mu \mathrm{M}^{-1}$.

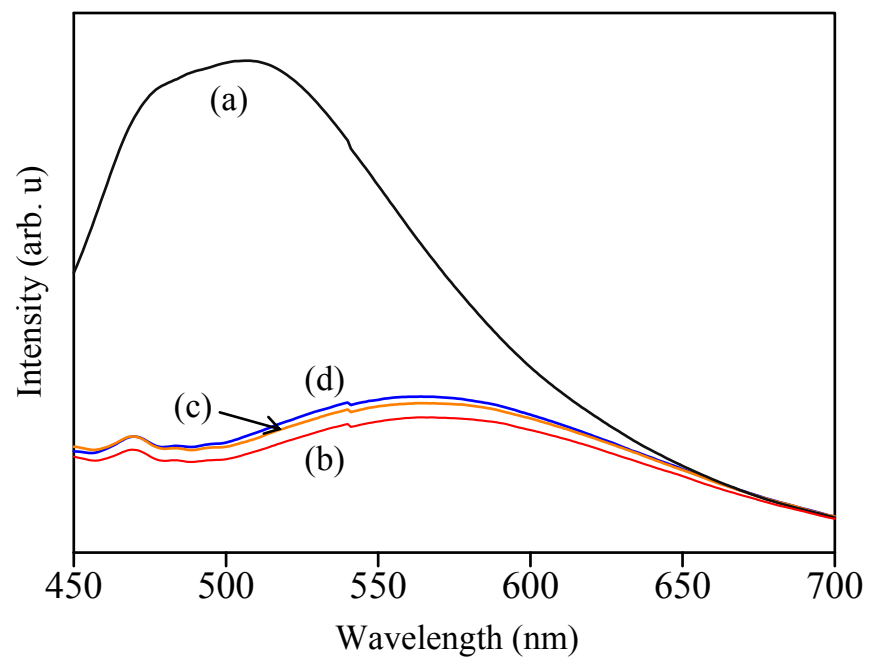

Fig. 3 Emission spectra for (a) $\mathrm{ZnO}$, (b) $\mathrm{PVP}(0.1) / \mathrm{ZnO}$, (c) $\mathrm{PVP}(1) / \mathrm{ZnO}$, and (d) $\mathrm{PVP}(3) / \mathrm{ZnO}$

Similar linear Stern-Volmer plots were also obtained on the PVP/ZnO samples (not shown). These results suggested that the PVP/ZnO samples were also able to interact with the $\mathrm{NO}_{2}^{-}$. The comparison on the $K_{s v}$ values between the $\mathrm{ZnO}$ and the PVP/ZnO is shown in Fig. 5. It was clear that the addition of PVP gave improvement on the $K_{s v}$ value of the $\mathrm{ZnO}$ when the loading of the PVP was low, i.e., $0.1 \mathrm{wt} \%$. The $K_{s v}$ value increased from 0.04 to $0.05 \mu \mathrm{M}^{-1}$. This $25 \%$ improvement showed the contribution of the PVP to increase the interaction to the $\mathrm{NO}_{2}$. Unfortunately, when the loading of PVP increased to 1 or 3 wt $\%$, the $K_{s v}$ value of the $\mathrm{ZnO}$ decreased since the high loading of PVP may block the emission sites of the $\mathrm{ZnO}$. Less emission sites of the $\mathrm{ZnO}$ would result in the less sensitivity. This study showed that only small loading of 
PVP can help to improve the interaction between the $\mathrm{ZnO}$ and the $\mathrm{NO}_{2}^{-}$.

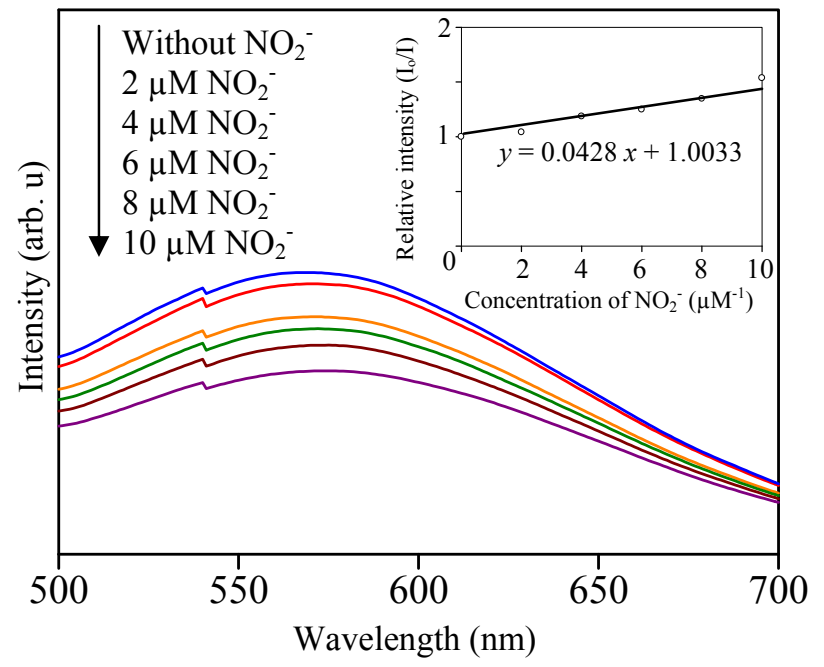

Fig. 4 Quenching of the emission intensity for the $\mathrm{ZnO}$ with the presence of $\mathrm{NO}_{2}^{-}(2-10 \mu \mathrm{M})$. The inset shows the Stern-Volmer plot for the $\mathrm{ZnO}$

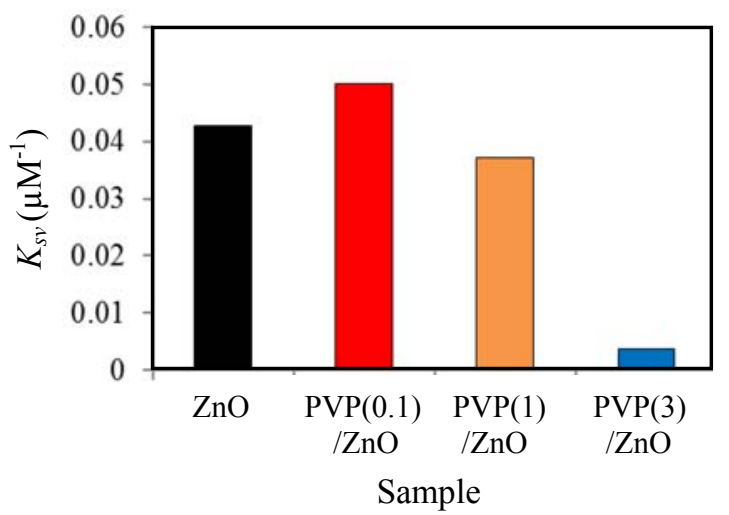

Fig. $5 K_{S V}$ values of the $\mathrm{ZnO}$ and the $\mathrm{PVP} / \mathrm{ZnO}$ composites

\section{CONCLUSION}

The $\mathrm{ZnO}$ and $\mathrm{PVP} / \mathrm{ZnO}$ composites were successfully synthesized via co-precipitation and simple physical mixing methods, respectively. The FTIR and DR UV-Vis spectra showed that the addition of the PVP did not change the chemical properties of $\mathrm{ZnO}$. The fluorescence spectra showed that addition of the PVP reduced the emission intensity and caused shifting of the emission peak. From the quenching study, the linear SternVolmer plots for $\mathrm{ZnO}$ and $\mathrm{PVP} / \mathrm{ZnO}$ in the presence of $\mathrm{NO}_{2}{ }^{-}$with various concentrations suggested the good interaction between the $\mathrm{ZnO}$ and the $\mathrm{PVP} / \mathrm{ZnO}$ composites towards the $\mathrm{NO}_{2}^{-}$. Only modification with small amount of the PVP $(0.1 \mathrm{wt} \%)$ can give a $25 \%$ improvement on the $\mathrm{K}_{S V}$ value of the $\mathrm{ZnO}$.

\section{ACKNOWLEDGEMENTS}

This work was financially supported by the Ministry of Higher Education (MOHE, Malaysia) and the Universiti Teknologi Malaysia (UTM, Malaysia) through a Tier-1 Research University Grant (cost center code: Q.J130000.2509.06H66). I.H.T acknowledges the support of MyBrain MyPhd scholarship.

\section{REFERENCES}

[1] S.S. Kumar, P. Venkateswarlu, V.R. Rao, Int. Nano Lett. 3 (2013) 1.

[2] A. Kołodziejczak-Radzimska, E. Markiewicz, T. Jesionowski, J. Nanomater. (2012) 1.

[3] B. Dindar, S. Içli, S. J. Photochem. Photobiol. A: Chem. 140 (2001) 263.

[4] D. Li, H. Haneda, H. Chemosphere. 51 (2003) 129.

[5] S. Ma, R. Li, C. Lv, W. Xu, X. Gou J. Hazard. Mater. 192 (2011) 730 .

[6] Z. Guo, G.-H. Kim, I. Shin, J. Yoon, Biomater. 33 (2012) 7818

[7] M. Badea, A. Amine, G. Palleschi, D. Moscone, G. Volpe, A. Curulli, J. Electroanal. Chem. 509 (2001) 66.

[8] Z. L. Wang, J. Phys.: Condens Matter 16 (2004) R829.

[9] H.-M. Xiong, X. Zhao, J.-S. Chen, J. Phys. Chem. B 105 (2001) 10169.

[10] C. Ton-That, M.R. Phillips, T.-P. Nguyen, J. Lumin 128 (2008) 2031.

[11] Y. Wang, R. Shi, J. Lin, Y. Zhu, Energy Environ. Sci. 4 (2011) 2922.

[12] D. Sun, H.-J. Sue, Appl Phys. Lett. 94 (2009) 253106.

[13] I. H. Tang, R. Sundari, H. O. Lintang, L. Yuliati, Malaysian J. Anal. Sci., accepted.

[14] S. Suwanboon, P. Amornpitoksuk, S. Muensit, J. Ceram. Process Res. 11 (2010) 419.

[15] S. Liufu, H. Xiao, Y. Li, Powder Technol. 145 (2004) 20.

[16] M.A.F. Basha, J. Polymer 42 (2010) 728.

[17] M. L. Singla, M. Kumar, J. Lumin. 129 (2009) 434.

[18] Y. Borodko, H.S. Lee, S.H. Joo, Y. Zhang, G. Somorjai, J. Phys. Chem. C 114 (2009) 1117.

[19] S. Tachikawa, A. Noguchi, T. Tsuge, M. Hara, O. Odawara, H. Wada, Materials 4 (2011) 1132.

[20] A.M. Stoneham, Rep. Prog. Phys. 44 (1981) 1251.

[21] J. R. Lakowicz, Principles of Fluorescence Spectroscopy, third ed., Springer, New York, 2006.

[22] B. Kumar, K. Smita, L. Kumbal, A. Debut, Bioinorg. Chem. Appl. (2014) 1 . 